\section{DISCUSSION}

The results of Experiments $I$ and II are consistent with previous investigations that reported an increase in gregariousness in rat pairs over days (Latané \& Glass, 1968; Latané, 1969). The rates of aggressive, submissive, and other social behaviors are fairly consistent over days. While the rates of aggressive or submissive behaviors were fairly consistent within pairs across days, there were large differences in the frequencies of these behaviors between pairs. Once a rat established dominance over his partner, their aggressive and submissive behaviors remained constant, although there were many differences between different rat pairs. Experiment II suggests that in the open-field-testing situation, 5- or 15-min observation periods produce comparable results for both quantitative and qualitative aspects of behavior.

\section{REFERENCES}

Eckman, J., Meltzer, J. D., \& Latané, B. Gregariousness in rats as a function of familiarity of environment. Journal of Personality \& Social Psychology, 1969, 11, 107-114.

Grant, E. C. An analy sis of the social behaviour of the male laboratory rat. Behaviour, 1963, 21, 246-259.

Grant, E. C. \& Mackintosh, J. H. A comparison of the social postures of some common laboratory rodents. Behaviour, 1963, 21, 246-259.

Latané, B. Gregariousness and fear in laboratory rats. Journal of Experimental Social Psychology, 1969, 5, 61-69.

Latané, B., \& Glass, D. C. Social and nonsocial attraction in rats. Journal of Personality \& Social Psychology, 1968, 9, 142-146.

Latané, B., Joy, V., Meltzer, J., Lubell, B., \& Cappell, H. Stimulus determinants of social attraction in rats. Journal of Comparative \& Physiological Psychology, 1972, 79, 13-21.

Latané, B., Nesbitt, P., Eckman, J., \& Rodin, J. Long- and short-term social deprivation and sociability in rats. Journal of Comparative \& Physiological Psychology, 197 2, 81, 69-75.

Poplawsky, A., \& Johnson, D. A. Open-field social behavior of rats following lateral or medial septal lesions. Physiology \& Behavior, 1973, 11, 845-854.

\title{
Isolation, serial position, and rehearsal in free recall*
}

\author{
FRANCIS S. BELLEZZA $\dagger$ and GREGORY P. HOFSTETTER $\dagger \dagger$ \\ Ohio University, Athens, Ohio 45701
}

\begin{abstract}
If the superior recall of isolated, high-priority items is the result of selective rehearsal, then recall of these items will depend on both serial position and retention interval in a single-trial free-recall task. Using presentation times of $2 \mathrm{sec}$ and $5 \mathrm{sec}$ per item, predictions made from the selective-rehearsal hypothesis were supported. With both presentation times, recall of words adjacent to the recalled isolated words was poorer than corresponding control words.
\end{abstract}

If one item in a list of items is made conspicuous with respect to the rest of the items, this item will be learned better. This is the von Restorff effect. Also, if Ss are instructed to especially remember particular items in a list, then these items will be better recalled. The term isolated in the present discussion is used to describe those items that are both made conspicuous and which the Ss are instructed to especially recall. One explanation for better recall under these conditions is that the Ss selectively rehearse the isolated items at the expense of the other items in the list (Jenkins \&

*This research was supported in part by Grant OURC 437 made to the first author by the Ohio University Research Committee. This paper is sponsored by D. A. Johnson, who takes full editorial responsibility for its contents.

tRequests for reprints should be sent to Francis S. Bellezza, Department of Psychology, Ohio University, Athens, Ohio 45701 .

+Now at Central Michigan University, Mount Pleasant, Michigan.
Postman, 1948; Waugh, 1969). The mechanism of rehearsal also plays an important role in the dual-storage models of Atkinson and Shiffrin (1968) and of Waugh and Norman (1965). The degree to which items have been rehearsed can explain the primacy effect in single-trial free-recall learning; and what items are being rehearsed at the time of recall can explain the recency effect (Rundus \& Atkinson, 1970; Glanzer, 1972). If the degree of selective rehearsal of an item is dependent both on its serial position and on its isolation, then the probability of recall of an item is also dependent on its serial position and isolation (Bellezza \& Cheney, 1973). More specifically: (a) Isolated items which appear at the beginning or middle of a list should be recalled with a higher probability than corresponding control items. This is because the greater rehearsal of these items will lead to a higher probability of their being coded into long-term store (LTS). (b) Isolated items appearing very late in the list will not reside in short-term store (STS) 


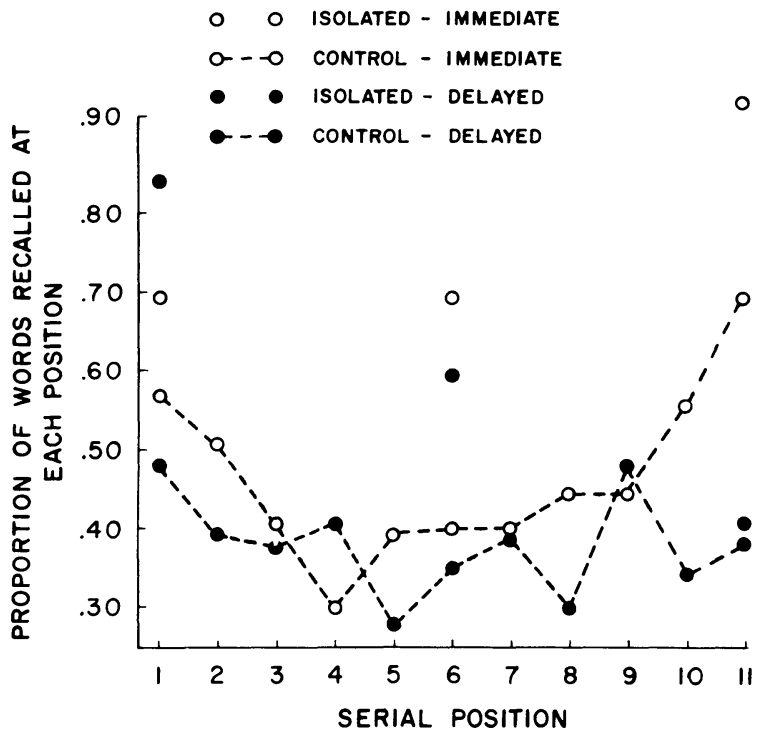

Fig. 1. Proportion of words recalled with a presentation time of $2 \mathrm{sec}$ per item.

long enough to be selectively rehearsed and coded into LTS. Under delayed-recall conditions, recall of these isolated items occurring at the end of the list should be no better than the recall of the control items. Under immediate recall, however, these isolated items are almost certain to be recalled because they are almost certain to be in STS. Bellezza and Cheney (1973) tested these predictions and found that, in general, (a) was supported. However, (b) was only partly supported by the data because delayed recall of the isolated items in the last serial position was significantly better than for the corresponding control items. It is possible that the interpolated task used following list presentation was not of sufficient difficulty to prevent some rehearsal of the isolated item. Kroll and Kellicutt (1972) have shown that counting backward by sevens is more effective in preventing rehearsal than counting backward by threes, which was the interpolated task used by Bellezza and Cheney. Therefore, in the present experiment, an interpolated task of counting backward by sevens was used. In addition, Bellezza and Cheney found that items adjacent to the recalled isolated items were less likely to be recalled than corresponding control items. Tulving (1969) found that items immediately preceding high-priority items were less likely to be recalled than control items at presentation times of $.5 \mathrm{sec}$ per item, but that the recall of immediately preceding items increased as presentation time increased to 1.0 and $2.0 \mathrm{sec}$ per item. Furthermore, Rundus (1971) found that recall of items adjacent to isolated items was enhanced. It may be that the presentation item of $5 \mathrm{sec}$ per item used by Rundus allowed Ss to selectively rehearse adjacent items along with the isolated item, but a presentation time less than this allows selective rehearsal only of the isolated item.
The purpose of the present experiment is to further test the selective-rehearsal hypothesis of the isolation effect by using an interpolated task more difficult than the one used previously. In addition, presentation times of both 2 and $5 \mathrm{sec}$ per item were used to determine if enhancement of recall of items adjacent to the isolated items takes place if more time per item is allowed for rehearsal.

\section{METHOD}

\section{Subjects}

The Ss were 64 volunteers drawn from a pool of introductory psychology students at Ohio University. The Ss received course credit for their participation.

\section{Procedure}

Each $\mathrm{S}$ received 12 lists each made up of 11 one-syllable words randomly drawn from Thorndike and Lorge and having a frequency of 10 to 40 per million. Each word was used only once for each S. The 12 lists were preceded by 4 practice lists which were not included in the analy sis. Sixteen different forms of the 12 lists were made up and four Ss were run on each form. For 32 of the Ss, the presentation time for each word was $2 \mathrm{sec}$, and for the other $32 \mathrm{Ss}$, the presentation time was $5 \mathrm{sec}$. Two Ss were run at each presentation time on each list form. After a list was presented, $\mathrm{S}$ was given $1 \mathrm{~min}$ to write down as many of the words presented as possible. The Ss were run individually using a Lafayette IBM memory drum. Six of the 12 lists on each form contained an underlined word at Serial Positions (SPs) 1, 6, or 11. The other 6 lists were control lists on which no words were underlined. The order of presentation of each type of list was randomized within each list form so that $S$ could not predict what type of list was to be presented. Each $S$ was instructed to recall as many words as he could, but was also told to recall especially the underlined word if one appeared in the list and to underline it when he wrote it down. On one-half of the control lists and on one-half of the isolated lists, recall was delayed for $20 \mathrm{sec}$, during which time $\mathrm{S}$ counted backward by sevens at the rate of one response every $2 \mathrm{sec}$ starting with a randomly generated three-digit number.

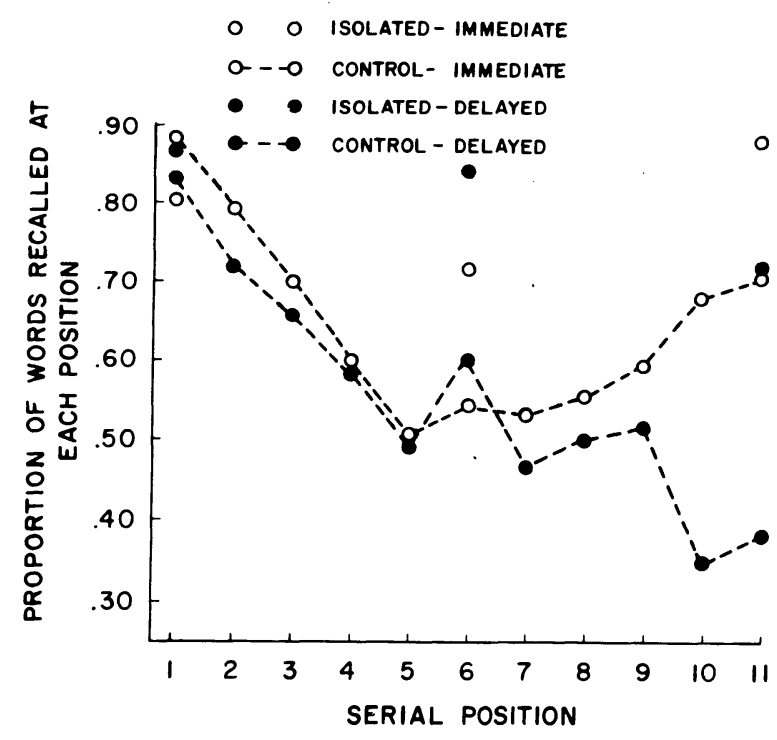

Fig. 2. Proportion of words recalled with a presentation time of $5 \mathrm{sec}$ per item. 
Table 1

Effects of Recall Condition and Isolation

\begin{tabular}{|c|c|c|c|c|c|c|}
\hline \multirow[b]{3}{*}{ Comparison } & \multicolumn{6}{|c|}{ Presentation Time } \\
\hline & Serial & Posi & ion & Serial & Posi & ion \\
\hline & 1 & 6 & 11 & 1 & 6 & 11 \\
\hline $\begin{array}{l}\text { Immediate Isolation } \\
\text { Immediate Control }\end{array}$ & .11 & $.29 \dagger$ & $.25 \dagger$ & -.06 & $.18^{*}$ & .17 \\
\hline $\begin{array}{l}\text { Delayed Isolation } \\
\text { Delayed Control }\end{array}$ & $.36 \dagger \dagger$ & $.24 \dagger$ & .03 & .04 & $.24 \dagger$ & $.34 \dagger \dagger$ \\
\hline
\end{tabular}

\section{Analysis}

The results of the experiment were evaluated using a 2 by 16 by 2 by 2 by 3 by 11 analysis of variance, with the specific factors being presentation time, list form, isolation condition, retention interval, position of isolation, and the serial position of each word recalled. Presentation time and list form were between-Ss factors. Each word was scored 1 if it was recalled and 0 if it was not. Misspelled words and plurals were accepted as correct. The analysis was done using the computer program BMD08V (Dixon, 1971).

\section{RESULTS}

The proportions of isolated words recalled at each serial position, compared to recall of items on the control lists with a presentation time of $2 \mathrm{sec}$, are shown in Fig. 1. Figure 2 shows recall using the presentation time of $5 \mathrm{sec}$ per item. Recall of each isolated word is based on 32 data points and recall of the control items is based on 96 data points because when no isolation was present the position-of-isolation conditions were identical. The complete serial position curves for lists containing an isolated word are not shown but are comparable to those presented by Bellezza and Cheney (1973). As predicted, the isolation of a word increased the probability of recall of that word, for the Isolation Condition by Position of Isolation by Serial Position interaction was significant, $\mathrm{F}(20,640)=4.12, \mathrm{p}<.001$. The Retention Interval by Isolation Condition interaction was not significant, $\mathrm{F}(1,32)=1.13, \mathrm{p}<.25$, which means that the decrease in total recall on the isolated lists when recall was delayed reported by Bellezza and Cheney (1973) did not occur in this experiment. The predictions from the selective rehearsal hypothesis were tested for the 2- and 5-sec presentation times separately using a priori orthogonal contrasts (Kirk, 1968). Table 1 gives the results of these comparisons. In order to determine if items adjacent to the isolated items were recalled more or less than corresponding control items, the proportions of adjacent items recalled given recall of the isolated item were computed. The proportion recalled is lower for the isolated lists than it is for the control lists, and this is true for both presentation times. Using simple t tests: for $2 \sec , \mathrm{t}(7)=2.91, \mathrm{p}<.05$, and for $5 \sec \mathrm{t}(7)=4.32$, $p<.01$. If the spread of effect was measured by computing the proportion of adjacent items recalled, given presentation of an isolated item rather than its recall, the differences would be in the same directions but would be smaller in magnitude.

\section{DISCUSSION}

In general, the rehearsal explanation of the isolation effect was supported by the results. At SP 11 under delayed recall, no differences were predicted between the isolated and control items, but with a presentation time of $5 \mathrm{sec}$ per item, a difference was found. With $5 \mathrm{sec}$ to rehearse selectively the isolated item rather than only $2 \mathrm{sec}, \mathrm{S}$ may have had a better chance of coding the item into LTS before the interpolated task began. Because there was no difference between isolated and control words under these conditions with a 2-sec presentation time, it appears that counting backward by sevens at a rate of one response every $2 \mathrm{sec}$ is effective in preventing rehearsal. The result that recall of isolated items had an adverse effect on the recall of adjacent items when the presentation time was $2 \mathrm{sec}$ per item corresponds to the results of Bellezza and Cheney (1973). However, the same result occurred with a presentation time of $5 \mathrm{sec}$, which does not correspond to the enhancement of recall of adjacent items found by Rundus (1971) with the same presentation time. Rundus compared the recall of items adjacent to the isolated items with the recall of all nonisolated items in those lists where only one isolated item occurred. He also reported that overall recall of isolated lists was poorer than the overall recall of control lists. Therefore, the control value compared to the recall of adjacent items could have been biased and hence too low. Another possibility is that overt rehearsal may influence items adjacent to isolated items differently than does covert rehearsal. In general, the results of this experiment support the selective rehearsal hypothesis as an explanation of the isolation effect in single-trial free-recall learning.

\section{REFERENCES}

Atkinson, R. C., \& Shiffrin, R. M. Human memory: A proposed system and its control processes. In $K$. W. Spence and J. T. Spence (Eds.), The psychology of learning and motivation: Advances in research and theory. Vol. II. New York: Academic Press, 1968.

Bellezza, F. S., \& Cheney, T. L. Isolation effect in immediate and delayed recall. Journal of Experimental Psychology, $1973,99,55-60$.

Dixon. W. J. (Ed.) BMD, Biomedical computer programs. Berkeley: University of California Press, 1971.

Glanzer, M. Storage mechanisms in recall. In G. H. Bower (Ed.), The psychology of learning and motivation: Advances in research and theory. Vol. V. New York: Academic Press, 1972.

Jenkins, W. O., \& Postman, L. Isolation and "spread of effect" in serial learning. American Journal of Psychology, 1948, 61, 214-221.

Kirk, R. E. Experimental design procedures for the behavioral sciences. Belmont: California: Wadsworth, 1968.

Kroll, N. E. A., \& Kellicutt, M. H. Short-term recall as a function of covert rehearsal and of intervening task. Journal of Verbal Learning \& Verbal Behavior, 1972, 11, 196-204.

Rundus, D. Analy sis of rehearsal processes in free recall. Journal of Experimental Psychology, 1971, 89, 63-77.

Rundus, D., \& Atkinson, R. C. Rehearsal processes in free recall: $A$ procedure for direct observation. Journal of Verbal Learning \& Verbal Behavior, 1970, 9, 99-105.

Tulving, E. Retrograde amnesia in free recall. Science, 1969, 164, 88-90.

Waugh, N. C. Free recall of conspicuous items. Journal of Verbal Learning \& Verbal Behavior, 1969, 8, 448-456.

Waugh, N. C., \& Norman, D. A. Primary memory. Psychological Review, 1965, 72, 89-104.

(Received for publication February 19, 1974.) 